which had been prevalent in the hospital some two months previously, and which, indeed, seemed epidemic in other hospitals in Manchester about that time, was so far unfortunate in that it not only subjected the patient to the dangers of another diseased condition, but, further, it was the cause of delay in healing, and of the consequent prolonged exposure of a large vessel to constant bathing in pus. In this, as in other cases of erysipelas occurring about the same period, the most effectual local treatment was that recently advocated by Mr. Barwell-viz., painting with white lead. The prognosis of the case is of course doubtful. Possibly the growth may recur. Up to the present time, however, there are no indications of its so doing. This possibility was considered at the time of operation. It was clear, however, that even amputation would have given no greater security against recurrence, seeing that the tumour was so situated that flaps could not possibly have been cut freer from the growth than were the margins of the incisions adopted. An interesting point in connexion with prognosis is the consideration of whether the erysipelatous condition might not exercise a possible deterrent influence upon recurrence of the growth, such as is ascribed to it in regulating the increase of actually existing malignant growths.

\section{KASHMIR HOSPITAL.}

CASE OF FROST-BITE; AMPUTATION OF BOTH LAGS; RECOVERY.

(Under the care of Mr. ARThur Neve.)

A KASHMIR porter, having been taken ill, was put into a boat, but barbarously turned ont at night by the boatmen and compelled to sleep on the bank. His feet were frostbitten fifteen days after ; and he was brought to the hospital with both feet nearly dropping off, and gangrene extending slightly up the legs. He appeared utterly exhausted.

Amputation was at once performed ; on the right leg, four inches above the ankle, with an internal flap from diseased but evidently tough skin; on the left leg at the upper third, also by lateral flaps. Very little blood was lost. The operation was performed under the spray, and the flaps were washed with a solution of chloride of zinc. The wound was stitched with chromic and catgut, lightly sprinkled with iodoform, and dressed with carbolised gauze.

On the following day the patient expressed relief, and seemed better. The dressings were changed on the second, fifth, eighth, eleventh, fifteenth, and eighteenth days, by which time all but the drainage-tube sinuses were perfectly healed. The wound of the right leg progressed uninterruptedly, and remained quite aseptic. Six weeks after the operation it could be trusted to bear the weight of the body. That of the left stump was found on the second day tense, and some stitches had to be remeved; on the fifth day it was putrid. It was injected with solutions of trichlorphenol and chloride of zinc, and sprinkled freely with iodoform, and healed as favorably as the other leg.

Remarks. - Frost-bite is common among the ill-clad natives of Kashmir. Most natives would, however, rather die than be " mutilated" by amputation. Probably the separative natural process alone reconciled this patient to the amputation. Improvement in his general condition was at once visible. When admitted he had a bedsore, which healed in about a week. The position of the wounds was chosen with a view to resting the right stump in a boot, the left knee on a wooden leg. On the right side it was performed through partially diseased tissue, in order to retain the skin of the ankle, which is usually in coolies very tough. The fact that this wound trenching so closely upon absolutely gangrenous tissue did not become putrid even when the otber stump did, is a testimony to the efficacy of the antiseptic measures employed. Recent extensive experience in a hospital specially calculated to breed bacteria leads me to value iodoform very highly, even when so sparingly employed that only an ounce would be used in the whole treatment of a dozen major cases, or ten grains to each dressing of an amputation wound. The amputation on the left side was by lateral flaps in order not to go higher up, which a long anterior flap would have necessitated. When the front angle of the wound is near the fibula, a very neat stump, not specially liable to injury, results. I have operated in three or four cases thus, always satisfactorily. This is, I believe, the first case in Kashmir where amputation of both legs has been followed by recovery.

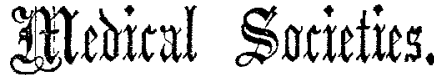

\section{OBSTETRICAL SOCIETY OF LONDON.}

A MeETING of this Society was held on Wednesday, June 4th, Dr. Gervis, President, in the chair.

The following specimens were shown :-Prolapsed Uterus removed with a fatal result, by Dr. Malins; Ovarian Cyst which ruptured into the abdominal cavity, the fluid being afterwards partially discharged through an ulcerated umbilical hernia, by Dr. Walter of Manchester; Meyer's Dilators for any cavity, by Dr. Aveling; a specimen of Spondylolisthesis, by Dr. Graily Hewitt and Mr. Shattock; a drawing of Chronic Papillary Inflammation of the Vulva, by Dr. Priestley; an Ovary showing commencing Cystic Disease, by Dr. Barnes; Fundus Uteri removed for in. version of four years' duration, by Dr. Mansell-Moullin. Placenta from a case of triplets, by Dr. Horrocks; Ayres' Electric Speculum, by Dr. Heywood Smith.

Spontaneous Absorption and Recovery after Pulmonary Thrombosis, by Dr. W. S. PlAYFAIR. - In this paper the author records a case of serious illness and recovery following a protracted and difficult labour. He analyses the symptoms and attempts to show that they could only be explained on the hypothesis of a thrombosis deposited in the pulmonary artery becoming spontaneously absorbed. He points out that the possibility of recovery under such conditions has not been sufficiently recognised. A second case is also recorded in the paper.-Dr. BROADBENT had seen the second of Dr. Playfair's cases ; there were no pelvic signs, but there were the following signs connected with the chest: one or two paroxysms of dyspnoea; a peculiar murmur over the right auricle, followed by the signs of pulmonary em. bolism; the auricular murmur was replaced by a systolic pulmonary murmur and obscuration of the pulmonary second sound. The left posterior tibial vein had been inflamed, and the right iliac vein afterwards became obstructed. Recovery was complete, except that the right leg was still swollen.Dr. GALABIN thought that, in view of the facts of pathology, Dr. Playfair had in his earlier writings attributed too much to thrombosis. In the case stated by Dr. Broadbent he considered that the clot, first formed in the right auricle, had become detached and formed an embolus in the pulmonary artery.-Dr. BARNES referred to a former contribution to the Obstetrical Transactions, showing that in many cases embolism followed thrombosis. He was sure he had seen cases recover from pulmonary embolism.-Dr. WILTSHIRE had seen a case of recovery after puerperal pulmonary thrombosis. He agreed with Dr. Playfair's diagnosis of the second case, but thought the first case was one of ulcerative endocarditis.-Dr. BRoADBENT replied to Dr. Galabin that he did not think there had been embolism of the trunk of the pulmonary artery, but that the clot had extended into it from the auricle, and an embolus detached from it had settled in the left lung. An embolic clot, if free, would not lodge in the pulmonary artery. He thought clots were removed rather by disintegration than absorption.-Dr, PLAYFAIR, in reply, stated that many of the objections had already been answered elsewhere, that thrombosis occurred within a few days after delivery, embolism not till the lapse of two or three weeks, a period required for the softening and detachment of a clot. He did not believe that either case was due to ulcerative endocarditis, the murmur must continue as long as the clot remained.

On Fotal Revolutions, by Dr. J. MATTHEws DunCANThe author regards revolutions (as distinct from rotations) as having been too much neglected in studying the mechanism of delivery. He shows the difficulty introduced by the peculiar curvature of the genital passages, which is nearer a parabola than a circle (circle of Carus). He shows that special mechanisms, as of the delivery of the head, extension, flexion, are imperfectly described and misunderstood, because not studied as parts of the change of fotal attitude neces. sitated by the revolution. Revolution generally involves extension of the whole foetal body. The various forms of revolution observed in different presentations and conditions of the fœetus are then described.-The PREsIDENT expressed his approval of the paper.-Dr. GALABIN criticised the accuracy of Dr. Duncan's description on the principles of geometry, and objected to the fotus being likened to a viscons mass although it was plastic to some extent, it came mechanically 